\title{
Oral Anticoagulation Therapy and Progression of Calcific Aortic Valve Stenosis: Factor Xa versus Factor Ila Inhibition?
}

\author{
Lisa Dannenberg Saif Zako Philipp Mourikis Verena Veulemans Malte Kelm \\ Tobias Zeus Amin Polzin \\ Department of Cardiology, Pulmonology, and Vascular Medicine, Medical Faculty of the Heinrich Heine University \\ Düsseldorf Cardiovascular Research Institute Düsseldorf (CARID), Düsseldorf, Germany
}

Comment reffering to: Tastet L, Pibarot P, Shen M, Clisson M, Côté N, Salaun E, Arsenault M, Bédard É, Capoulade R, Puri R, Poirier P, Clavel MA. Oral Anticoagulation Therapy and Progression of Calcific Aortic Valve Stenosis. J Am Coll Cardiol. 2019 Apr;73(14):1869-71.

\section{Dear editor,}

In the highly interesting study by Tastet et al. [1], the authors were able to demonstrate that warfarin treatment is associated with faster progression of aortic valve stenosis as compared to direct oral anticoagulants (DOACs). The study is of great interest as aortic stenosis is the most frequent valve disease with a substantial socioeconomic impact. Furthermore, atrial fibrillation with indication to permanent oral anticoagulation is common in those patients. However, detailed mechanisms that explain this highly interesting finding remain unclear.

Vascular calcification is increased by vitamin-K anticoagulant (VKA) medication both in patients and in mice [2]. Mechanistically, vitamin K cycle inhibition hinders the gamma-carboxylation of the calcification inhibitor Gla protein and moreover decreases the expression of GIa in plaque material [2]. This leads to calcification of the aortic valve. However, translational studies of human valve material are missing. In patients with chronic kidney disease
(CKD), VKA have been shown to enhance progression of calciphylaxis [3]. Impressively, stopping of VKA treatment even led to healing of calciphylaxis associated lesions that recurred after retreatment with VKA after 1 year [3].

Regarding the recent study by Tastet et al. [1], additional analyses would be intriguing. By now, many patients on VKA were switched to DOACs, as current guidelines recommend DOACs over VKA in patients with atrial fibrillation. In patients with CDK stages 3 and 4 , rivaroxaban has already been shown to reduce deposition and progression of cardiac valve calcification compared to VKA medication [4]. Hence, does switching from VKA to DOAC medication have an impact on progression of AS? To date, factor IIa and factor Xa inhibition are available as different types of DOACs. We could show that there are substantial differences between factor IIa- and factor Xa inhibition [5]. In the study by Tastet et al. [1], DOACs were not separated in factor II and factor Xa inhibitors. This might be interesting to investigate potentially differentiating effects on the progression of AS.

\section{Acknowledgments}

None.

Funding Source

None.

\section{Author Contributions}

L.D., S.Z., M.K., V.V., T.Z., and A.P. wrote the manuscript.

\section{Disclosure Statement}

The authors have no conflicts of interest to declare.

\section{KARGER}

(c) 2019 S. Karger AG, Basel
PD Dr. med. Amin Polzin

Klinik für Kardiologie

Pneumologie und Angiologie

Moorenstrasse 5, DE-40225 Düsseldorf (Germany)

E-Mail amin.polzin@med.uni-duesseldorf.de 


\section{References}

1 Tastet L, Pibarot P, Shen M, Clisson M, Côté N, Salaun E, et al. Oral Anticoagulation Therapy and Progression of Calcific Aortic Valve Stenosis. J Am Coll Cardiol. 2019 Apr;73(14): 1869-71.

2 Schurgers LJ, Joosen IA, Laufer EM, Chatrou ML, Herfs M, Winkens $\mathrm{MH}$, et al. Vitamin K-antagonists accelerate atherosclerotic calcification and induce a vulnera- ble plaque phenotype. PLoS One. 2012;7(8): e43229.

3 Russ P, Russwurm M, Kortus-Goetze B, Hoyer J, Kamalanabhaiah S. Phenprocoumon based anticoagulation is an underestimated factor in the pathogenesis of calciphylaxis. BMC Nephrol. 2019 Apr;20(1):114.

4 Di Lullo L, Tripepi G, Ronco C, D’Arrigo G, Barbera V, Russo D, et al. Cardiac valve cal- cification and use of anticoagulants: preliminary observation of a potentially modifiable risk factor. Int J Cardiol. 2019 Mar;278: 243-9.

5 Achilles A, Mohring A, Zeus T, Kelm M, Polzin A. Dabigatran enhances platelet reactivity and platelet thrombin receptor expression in patients with atrial fibrillation: reply. Thromb Haemost. 2017 Jul;15(7):1524-5. 